\title{
ORIGINAL ARTICLE Inositol hexakisphosphate kinase-1 regulates behavioral responses via GSK3 signaling pathways
}

\author{
A Chakraborty ${ }^{1,5,6}$, C Latapy ${ }^{2,6}, \mathrm{~J} \mathrm{Xu}^{1}$, SH Snyder ${ }^{1,3,4}$ and J-M Beaulieu ${ }^{2}$
}

\begin{abstract}
Glycogen synthase kinase 3 (GSK3), a prominent enzyme in carbohydrate metabolism, also has a major role in brain function. It is physiologically regulated by the kinase Akt, which phosphorylates GSK3 to inhibit catalytic activity. Inositol hexakisphosphate-1 (IP6K1) generates the inositol pyrophosphate diphosphoinositol pentakisphosphate (IP7), which physiologically inhibits Akt leading to enhanced GSK3 activity. We report that IP6K1 binds and stimulates GSK3 enzymatic activity in a non-catalytic fashion. Physiological relevance is evident in the inhibition of GSK3 activity in the brains of IP6K1-deleted mice. Behavioral alterations of IP6K1 knockout mice resemble those of GSK3 mutants. Accordingly, modulation of IP6K1-GSK3 $\beta$ interaction may exert beneficial effects in psychiatric disorders involving GSK3.
\end{abstract}

Molecular Psychiatry (2014) 19, 284-293; doi:10.1038/mp.2013.21; published online 26 February 2013

Keywords: behavior; GSK3; IP6K1

\section{INTRODUCTION}

Glycogen synthase kinase 3 alpha and beta (GSK3 $\alpha$ and GSK3 $\beta$ ) are prominent signaling serine/threonine protein kinases mediating responses to neurotransmitters and hormones. ${ }^{1-3}$ Despite being considered as constitutively active, the enzymes are regulated by diverse factors. ${ }^{4}$ In the classic growth factor signaling cascade, a variety of intercellular signals, which often converge upon tyrosine kinases, lead to activation of PI3 kinase (PI3K) that generates the phospholipid phosphatidylinositol 3,4,5trisphosphate (PIP3). ${ }^{5}$ PIP3 recruits the protein kinase Akt to the plasma membrane where it is activated by phosphorylation at its threonine (T308) and serine (S473) residues, respectively, by phosphoinositide-dependent kinase-1 (PDK1) ${ }^{6}$ and mTORC2. ${ }^{7}$ Akt in turn inhibits both GSK3 isoforms by phosphorylating the regulatory serine residues S21 (GSK3 $\alpha$ ) and S9 (GSK3 $\beta)^{3,8,9}$

While Akt/GSK3 signaling has been most extensively studied in response to mitogenic stimuli, the system is also prominent in the brain and has been linked to psychiatric diseases. ${ }^{10,11}$ Neurotransmitters such as dopamine, in response to amphetamine, can impact Akt/GSK3 via a pathway wherein activation of D2 receptors recruits $\beta$-arrestin 2, a scaffolding protein that elicits receptor desensitization and signalization. ${ }^{12-15}$ In rodent brain, D2 receptor activation triggers the formation of a signaling complex incorporating $\beta$-arrestin 2 , Akt and the protein phosphatase PP2A, which dephosphorylates and inactivates Akt leading to increased GSK3 activity. ${ }^{14}$ Conversely, antipsychotic drugs, by blocking D2 receptors, prevent $\beta$-arrestin 2 recruitment and thereby stimulate Akt and inhibit GSK3 activity. ${ }^{16}$ The mood stabilizer lithium, at therapeutic concentrations, disrupts the $\beta$-arrestin 2/Akt/PP2A complex thereby activating Akt and inhibiting GSK3. ${ }^{17,18}$ Influences of lithium upon this recently reported signaling protein complex provide an alternative mode for the well-known direct inhibition of GSK3 by lithium. ${ }^{14,19,20}$

Apart from the classic PI3K/Akt pathway, GSK3 is also an integral part of the Wnt signaling complex. ${ }^{20-22}$ GSK3 activity is enhanced in the absence of Wnt through a complex formation with adenomatosis polyposis coli protein, Axin and $\beta$ catenin. ${ }^{23}$ Activation of Wnt inhibits GSK3 activity by recruiting GSK3binding protein/Frat1, which inhibits GSK3 by displacing it from the destruction complex. As a result, $\beta$ catenin is stabilized, enters the nucleus and triggers transcription of Wnt target genes. ${ }^{23}$

Several lines of evidence link Akt, and consequently GSK3, to schizophrenia and related psychiatric disorders. ${ }^{24-26}$ AKT1 haplotypes cosegregate with schizophrenia, implicating the enzyme as a schizophrenia susceptibility gene, a possibility supported by the association of polymorphisms in this same gene with dopamine-associated behavior in schizophrenia. ${ }^{26-28}$ Alterations in cognitive function are linked to the Akt genotype in schizophrenics. ${ }^{11}$ Akt levels are reduced substantially in lymphocytes from a subset of schizophrenics as well as in postmortem schizophrenic brain, in which levels of phosphorylated GSK3 $\beta$ are also diminished. ${ }^{26}$ Akt/GSK3 $\beta$ signaling influences synaptic plasticity as monitored by long-term potentiation and depression in rodents. ${ }^{29,30}$ GSK3 has also been implicated in various neuropsychiatric disorders via its links with Wnt signaling based in part on its modulation by typical and atypical antipsychotic medications. ${ }^{24}$

Inositol phosphates are widely distributed in animal and plant tissues. Inositol 1,4,5-trisphosphate (IP3), the most studied inositol phosphate, signals by releasing intracellular calcium. ${ }^{31}$ The inositol pyrophosphates are recently appreciated signaling molecules, ${ }^{32,33}$ which regulate diverse cellular processes, including insulin

\footnotetext{
${ }^{1}$ The Solomon H. Snyder Department of Neuroscience, Johns Hopkins University School of Medicine, Baltimore, MD, USA; ${ }^{2}$ Department of Psychiatry and Neurosciences, Université Laval, Quebec, QC, Canada; ${ }^{3}$ Department of Psychiatry and Behavioral Sciences, Johns Hopkins University School of Medicine, Baltimore, MD, USA and ${ }^{4}$ Department of Pharmacology and Molecular Sciences, Johns Hopkins University School of Medicine, Baltimore, MD, USA. Correspondence: Dr SH Snyder, The Solomon H. Snyder Department of Neuroscience, Johns Hopkins University School of Medicine, 725 N Wolfe Street, WBSB no. 813, Baltimore, MD 21205, USA or Dr J-M Beaulieu, Department of Psychiatry and Neurosciences, Université Laval, Quebec, QC, Canada.

E-mail: ssnyder@jhmi.edu or martin.beaulieu@crulrg.ulaval.ca

${ }^{5}$ Current address: Department of Metabolism and Aging, The Scripps Research Institute, Jupiter, FL 33458, USA.

${ }^{6}$ These authors contributed equally to this work.

Received 13 November 2012; revised 21 December 2012; accepted 2 January 2013; published online 26 February 2013
} 
signaling and weight gain, ${ }^{34}$ insulin release, ${ }^{35}$ energy homeostasis, ${ }^{36}$ neutrophil phagocytosis, ${ }^{37}$ embryonic development, ${ }^{38}$ telomere length maintenance, ${ }^{39,40}$ phosphate homeostasis ${ }^{41}$ and apoptosis. ${ }^{42-46}$ Phosphorylation of inositol hexakisphosphate (IP6) by a family of IP6 kinases (IP6Ks) generates diphosphoinositol pentakisphosphate (PP-IP5 or IP7), ${ }^{47}$ which contains a diphosphate whose free energy is comparable to that of ATP enabling it to pyrophosphorylate target proteins. ${ }^{48,49}$ IP7 can also signal by directly inhibiting Akt. $^{34}$ The physiological relevance of this inhibition is evident in the major augmentation of Akt signaling in IP6K1-deleted mice (IP6K1-KO). ${ }^{34,37}$ Consequently, IP6K1-KO mice are protected against weight gain and insulin resistance. ${ }^{34}$

Though IP6K1 is highly expressed in brain, 47,50 its neuronal functions have not been studied. In the present study, we report that IP6K1 binds both GSK3 $\alpha$ and $\beta$ and physiologically stimulates their catalytic activities. IP6K1 enhances GSK3 catalytic activity in vitro in a catalytically independent mechanism. IP6K1-KO mice display significant reduction in GSK3 activity in diverse brain regions. The behavioral phenotype of IP6K1-KO mice is consistent with these signaling alterations indicating that IP6K1 is a physiological activator of GSK3.

\section{MATERIALS AND METHODS}

Materials

Mice. Generation of IP6K1-KO mice were described previously.51 IP6K1KO mice were inbred up to six generations with C57BL/6 mice. Three- to four-month-old male littermates were used for studies. Animal care and experimentations were approved by the Johns Hopkins University Animal Care and Use Committee. Mice were housed in a 12-h light/12-h dark cycle, at an ambient temperature of $22^{\circ} \mathrm{C}$, and fed standard rodent chow.

Antibodies. Horseradish peroxidase (HRP)-conjugated $\alpha$-GST (Sigma-Aldrich, St Louis, MO, USA), HRP-conjugated light-chain-specific $\alpha$-lgG (Jackson Immunoresearch, West Grove, PA, USA), $\alpha$-IP6K1 (Genetex, Irvine, CA, USA), $\alpha$-GSK3 $\alpha / \alpha$-GSK3 $\beta$ (Millipore, Billerica, MA, USA). All other antibodies were purchased from Cell Signaling Technology (Danvers, MA, USA).

Proteins. Purified recombinant active Akt and GST-GSK3 $\beta$ (rat) were from Millipore; untagged GSK3 $\beta$ purified from bacteria was from New England Biolabs (Ipswich, MA, USA). Recombinant human Tau-441 protein was purchased from Signalchem (Richmond, BC, Canada).

Pharmacological inhibitors. TDZD-8 (EMD Biosciences, San Diego, CA, USA), SB216763 and SB415286 (Cayman Chemicals, Ann Arbor, MI, USA), Amphetamine (Tocris Bioscience, Ellisville, MO, USA).

Other chemicals. All the other chemicals were purchased from SigmaAldrich, unless otherwise stated. Proteins and peptides: Active GSK3 $\beta$ (New England Biolabs), CREB phosphopeptide (Anaspec, Freemont, CA, USA). The following clones were purchased from Addgene (Cambridge, MA, USA): pCDNA3-HA-GSK3 $\beta$ WT (14753), pCDNA-HAGSK3 $\beta$ K85A (14755) (Jim Woodgett Lab).

\section{Methods}

IP6K1-GSK3 co-immunoprecipitation. Cortical and hippocampal tissues were isolated from WT and IP6K1-KO mice and lysed with a buffer containing $20 \mathrm{~mm}$ Tris- $\mathrm{Cl}(\mathrm{pH} 7.4), 150 \mathrm{~mm} \mathrm{NaCl}, 1 \%$ Trion X-100, protease and phosphatase inhibitors. Equal concentrations of proteins (1.5 $\mathrm{mg}$ each) were incubated with rabbit IgG and protein $A / G$ sepharose beads for $30 \mathrm{~min}$ to pre-clear the lysates. Beads were discarded and the supernatants were used for immunoprecipitation overnight by control lgG or $2.5 \mu \mathrm{g}$ $\alpha-I P 6 K 1$ antibody and protein A/G sepharose beads. Next day, beads were washed $3 \times$ with wash buffer (lysis buffer without protease/phosphatase inhibitors) and boiled with LDS-buffer for SDS-polyacrylamide gel electrophoresis (SDS-PAGE) analysis of IP6K1 and GSK3 3 . To avoid detection of heavy chain antibody by western blotting, HRP-conjugated light chain-specific antibody was used for IP6K1 and GSK3 $\beta$ detection.

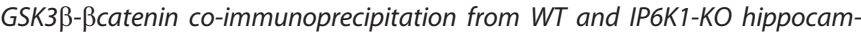
pal extracts. Hippocampal extracts were prepared from WT and IP6K1-KO mice. Extracts from two WT and three KOs (shown in Figure 3e) were pooled together. Total $750 \mu \mathrm{g}$ of proteins were used for the immunoprecipitation experiment after preclearing the lysates with $\alpha$-IgG. $\alpha$-GSK3 $\beta$ antibody and protein $A / G$ beads (EMD Biosciences) were added to the lysates and rotated at $4{ }^{\circ} \mathrm{C}$ for overnight. Samples were processed for western blotting as described earlier and were detected with $\alpha$ - $\beta$ catenin and $\alpha$-GSK3 $\beta$ antibodies.

GST pull-down assay. GST or GST-IP6K1 was overexpressed in HEK293 cells using polyfect transfection reagent (Qiagen, Valencia, CA, USA). At $48 \mathrm{~h}$ post transfection, cells were lysed in lysis buffer. Equal concentrations of proteins were incubated overnight with glutathione-sepharose beads. Next day, beads were washed $3 \times$ with wash buffer. Beads were then boiled with LDS-buffer for SDS-PAGE analysis of GST-IP6K1 and endogenous GSK3 $\beta$.

To monitor IP6K1-GSK3 3 binding in presence of GSK3 inhibitors, indicated drugs were added ( $20 \mu \mathrm{m}$ of SB216763, SB415286 and TWS119 and $50 \mu \mathrm{m}$ of TDZD-8) to $10 \mathrm{~cm}$ plates $48 \mathrm{~h}$ post transfection for indicated time periods. Cells were lysed and assayed as described above.

For deletion-mapping experiments, GST-IP6K1 and Flag-GSK3 deletion fragments were co-overexpressed in HEK293 cells. Cells were lysed and processed following procedure described above.

IP6K1-GSK3 $\beta$ binding in vitro. Recombinant 6X-His-IP6K1 and GST-GSK3 $\beta$ $(1 \mu \mathrm{m}$ each) were incubated in binding buffer $(20 \mathrm{~mm}$ Tris- $\mathrm{Cl}(\mathrm{pH} 7.4)$, $150 \mathrm{~mm} \mathrm{NaCl}$ and $1 \%$ Triton X-100) in a total volume of $100 \mu \mathrm{l}$ for $30 \mathrm{~min}$ at room temperature. Glutathione-sepharose beads were added to the mixture and were incubated for $1 \mathrm{~h}$ with occasional mixing. Beads were washed $3 \times$ with wash buffer (similar to the binding buffer with $300 \mathrm{~mm}$ $\mathrm{NaCl}$ ). Samples were prepared for SDS-PAGE analysis.

GSK3 $\beta$ activity assay in vitro. GSK3 $\beta(50 \mathrm{~nm}$, New England Biolabs) was used in the assay with $50 \mu \mathrm{m}$ CREB phosphopeptide, $250 \mu \mathrm{m}$ Mg-ATP, $10 \mathrm{~mm}$ $\mathrm{MgCl}_{2}$ and [ $\left.\gamma 32 \mathrm{P}\right] A T P(1 \mu \mathrm{Ci})$ for $15 \mathrm{~min}$ at $30^{\circ} \mathrm{C}$. Purified recombinant human IP6K1-WT or IP6K1-KD (kinase-dead, K226A-S334A double mutant) were added at indicated concentrations in the assay. Reaction was stopped by addition of $50 \mathrm{~mm}$ EDTA. Reaction mixtures were spotted on P81 phosphocellulose papers (Millipore). Papers were washed $3 \times$ with $75 \mathrm{~mm}$ phosphoric acid to remove non-specific radioactivity. Papers were then dehydrated with methanol and counted in a liquid scintillation counter.

To monitor GSK3 $\beta$ activity on Tau, purified recombinant Tau $(1 \mu \mathrm{M})$ was used as GSK3 $\beta$ substrate with other conditions unchanged in presence of indicated concentrations of IP6K1. Reaction was boiled with LDS-buffer and run on an SDS-PAGE. Radiolabeled Tau was detected by autoradiography.

To assess IP6K1's effect on Akt-mediated GSK3 phosphorylation, active recombinant Akt was incubated with recombinant GST-GSK3 $\beta$ in presence of $100 \mu \mathrm{M}$ ATP, $1 \mathrm{~mm} \mathrm{MgCl} 2$ and indicated concentrations of recombinant IP6K1 for $30 \mathrm{~min}$. Reaction was stopped by addition of $25 \mathrm{~mm}$ EDTA. Samples were run on SDS-PAGE and immunoblotted against $\alpha$-pGSK3 (S9), $\alpha$-GST and $\alpha$-IP6K1 antibodies.

3[H]Myoinositol labeling of WT IP6K1-KO cortical neurons. IP6K1 heterozygous male and females were set for breeding. On the 18th day, cortical neurons were isolated from individual embryos, the body portions of which were genotyped simultaneously. Inositol labeling was started on 12-day-old neurons in culture. Inositol phosphates were processed 3 days post labeling following standard procedure. ${ }^{34,52}$

Purification of recombinant IP6K1-WT and IP6K1-KD. E. coli BL21 cells were transformed with pGEX6P2-IP6K1-WT and IP6K1-KD constructs. Single colony from each plate was grown in $100 \mathrm{ml}$ of Luria Bertani medium overnight in presence of ampicillin $100 \mu \mathrm{g} \mathrm{ml}^{-1}$ final concentrations. The overnight culture was transferred to 1 I fresh Luria Bertani medium with $100 \mu \mathrm{g} \mathrm{ml}^{-1}$ ampicillin, grown to $0.7-0.8 \mathrm{OD}_{600}(\sim 2-3 \mathrm{~h})$, then induced with $1 \mathrm{~mm}$ IPTG for $4 \mathrm{~h}$. Cells were pelleted and lysed by sonication with $30 \mathrm{ml}$ of lysis buffer ( $20 \mathrm{~mm}$ Tris, pH 7.4; $200 \mathrm{~mm} \mathrm{NaCl} ; 5$ mм DTT; $1 \%$ Triton $\mathrm{X}-100 ; 1 \mathrm{mg} \mathrm{ml}^{-1}$ lysozyme and protease inhibitor cocktails). Supernatant was taken after centrifugation. Glutathione sepharose ( $1 \mathrm{ml}$ packed beads) were equilibrated with $10 \mathrm{ml}$ of equilibration buffer $(20 \mathrm{~mm}$ Tris $+10 \mathrm{mg}$ bovine serum albumin). $300 \lambda$ beads were added to each sample, rotated at $4{ }^{\circ} \mathrm{C}$ for $2 \mathrm{~h}$. Beads were washed $3 \times$ with $10 \mathrm{ml}$ wash buffer (Lysis buffer without protease inhibitors and lysozyme). 
Prescission protease treatment. After the third wash, solution was removed from the beads. To $300 \lambda$ beads, $300 \lambda$ prescission protease buffer ( $50 \mathrm{~mm}$ Tris $7.5,150 \mathrm{~mm} \mathrm{NaCl}, 0.01 \%$ Triton X-100) and $1 \lambda$ protease were added and incubated overnight at $4{ }^{\circ} \mathrm{C}$. Proteins were frozen after adding $1 \mathrm{~mm}$ DTT and 20\% glycerol.

\section{Behavioral tests}

Drug administration. Amphetamine (Tocris Bioscience) was prepared in $0.9 \%$ saline solution and injected intraperitoneally (i.p.) in a volume of $10 \mathrm{ml} \mathrm{kg}^{-1}$ of body weight. 4-benzyl-2-methyl-1,2,4-thiadiazolidine-3,5dione (TDZD-8) was solubilized in a minimal volume of Tween (SigmaAldrich) then dissolved in $0.9 \%$ saline solution and injected i.p. in a volume of $10 \mathrm{ml} \mathrm{kg}^{-1}$ of body weight as described. ${ }^{53}$

Locomotor activity. Locomotion was assessed under illuminates conditions in an automated Omnitech digiscan apparatus (AccuScan Instrument Columbus, $\mathrm{OH}, \mathrm{USA}$ ) as described. ${ }^{53}$ For the evaluation of locomotor activity in a novel environment, mice were placed into the apparatus and their activity was monitored for $1 \mathrm{~h}$. The following parameters were measured: horizontal activity and vertical time. For tests involving drug treatment mice were placed in the locomotor activity monitor chamber for an acclimation period of $45 \mathrm{~min}$ before being injected with amphetamine or vehicle. After injection, mice were returned to the monitoring chamber and their locomotor activity was recorded for an additional $2 \mathrm{~h}$. For TDZD-8 response, locomotion was assessed under illuminated conditions in an automated Omnitech Digiscan apparatus (AccuScan Instrument) for $60 \mathrm{~min}$

Rotarod. Motor coordination was assessed using a rotarod (MedAssociates, Georgia, VT, USA). Control WT and IP6K1-KO mice were placed on an accelerating rotarod (2-20 r.p.m. in $5 \mathrm{~min}$ ). Mouse performed at four trials and fall latency is recorded allowing assessing the mean of latency to fall of each animal.

Preference for social novelty. Males mice were isolated for 2 weeks and placed in a three-compartment box as described. ${ }^{54}$ Mice were allowed to circulate freely in the three-compartment box for 5 min. Empty, inverted cups (Galaxy Pencil cup/Utility Cup Spectrum Diversified Designs, Streetsboro, $\mathrm{OH}, \mathrm{USA}$ ) were placed in each outer compartment. After this acclimation session, experimental mice were placed in the central compartment with doors closed, allowing the experimenter to introduce an unknown male (age-matched, C57BL/6) in one of the cups and an object of approximately the same size in the center of the other inverted cup. Then, both doors were simultaneously opened and, for a 10-min session (session 1), the tested mouse was free to explore all three compartments. After this, the mouse was placed back in the center compartment and the object was replaced by another unknown male mouse, while the first male remained in the same position. During the second session of the social novelty phase, the test mouse was again free to explore all three compartments for a 10-min session. During both test sessions, video tracking was performed and the amount of time spent sniffing the stranger mice or the object was recorded and analyzed using ANY-maze (Stoelting, Wood Dale, IL, USA).

Social interactions. Social interactions were performed in a transparent Plexiglas area with males being kept in isolation for 14 days before testing as described. ${ }^{55,56}$ Unfamiliar pairs of age and weight-matched animals were placed at the same time in the open field for $20 \mathrm{~min}$. A control C57BL/ 6 male and a mouse from the tested line made up each pair. For each pair of animals, the following parameters were measured: Time spent by the animals in active social interaction (including time spent sniffing, allogrooming, following, crawling, escaping and wrestling), and number of social events (sniffing, following, allogrooming, crawling) or non-social events (grooming, escape, wrestling, biting) initiated by each animal. For tests involving drug treatment, pairs were composed of two C57BL/6 males were one of them received one injection and were returned in the home cage $5 \mathrm{~min}$ before the test.

\section{Statistical analysis}

Behavioral analysis. To compare pairs of columns, data were analyzed by two-tailed student $t$-tests. Other behavioral studies (Figure $5 a, c$ and e) were analyzed using analysis of variance with Bonferroni post-hoc tests for multiple comparisons using GraphPad Prism software, Version 5.01
(Graphpad software, La Jolla, CA, USA). Data are presented as \pm s.e.m.; ${ }^{*} P \leqslant 0.05,{ }^{* *} P \leqslant 0.01$ and ${ }^{* * *} P \leqslant 0.005$.

Other experiments. Data from at least three independent experiments were plotted using Sigmaplot software. For western blotting experiments bands from three independent experiments were quantified using ImageJ software. Data are presented as \pm s.e.m. Statistical significance was calculated by Student's $t$-test using the Sigmaplot software $\left({ }^{* * *} P \leqslant 0.001\right.$; ${ }^{*} P \leqslant 0.01 ;{ }^{*} P \leqslant 0.05$ )

\section{RESULTS}

IP6K1 physiologically binds GSK3 kinase

IP6K1 influences the Akt/GSK3 pathway in peripheral tissues. We investigated neuronal interactors of IP6K1 in the PI3K/Akt pathway and discovered that IP6K1 interacts with GSK3. Overexpressed IP6K1 binds endogenous GSK3 $\alpha$ and $\beta$ in HEK293 cells (Figure 1a). Endogenous IP6K1 and GSK3 $\alpha / \beta$ bind, as evidenced by coimmunoprecipitation of the proteins from mouse cerebral cortical extracts (Figure $1 \mathrm{~b}$ ). Of the two isoforms, GSK3 $\beta$ binding is more prominent, so we focused upon GSK3 $\beta$ in subsequent experiments. We confirm the specificity of the in vivo protein interaction as GSK3 $\beta$ is not co-immunoprecipitated from IP6K1-KO tissue extracts (Figure 1c). The protein interactions are direct, as evidenced by the in vitro binding of purified IP6K1 and GSK3 $\beta$ (Figure 1d).

Binding of IP6K1 to GSK3 is dependent upon GSK3 catalytic activity. Thus, IP6K1-GSK3 $\beta$ interactions increase in the presence of the PI3K inhibitor wortmannin (Figure 1e), which stimulates GSK3 via Akt inhibition. ${ }^{57}$ We also monitored IP6K1-GSK3 $\beta$ binding in the presence of diverse GSK3 inhibitors of which TDZD-8, an ATP-non-competitive inhibitor ${ }^{58}$ disrupts IP6K1-GSK3 $\beta$ binding within $4 \mathrm{~h}$ (Figure 1f). Other GSK3 inhibitors also inhibit the binding after overnight treatment (Supplementary Figure 1).

We investigated the IP6K1-binding site on GSK3. The protein kinase is broadly divided into a N-terminal glycine rich domain, which possesses the inhibitory serine phosphorylation site, the middle kinase domain containing tyrosine autophosphorylation site and the C-terminal domain. ${ }^{59}$ Deletion analysis reveals that IP6K1 binds to the N-terminal (1-123) domain of GSK3 $\beta$ (Figure 1g). IP6K1 does not bind the catalytically inactive lysine85-alanine GSK3 $\beta$ mutant (Figure 1h). Thus, IP6K1 physiologically binds N-terminal domain of active conformation of GSK3.

\section{IP6K1 stimulates GSK3 kinase catalytic activity}

We assessed the influence of IP6K1 binding on GSK3 activity. With an in vitro assay using PCREB peptide as a GSK3 $\beta$ substrate, ${ }^{60}$ bacterially purified IP6K1-WT (Supplementary Figure 2) stimulates GSK3 $\beta$ catalytic activity fourfold, whereas $\mathrm{HSP}^{61}$ and bovine serum albumin display modest effects (Figure 2a). The stimulatory effect of IP6K1 does not depend on its active conformation, as catalytically inactive IP6K1 (IP6K1 K226A-S334A double mutant denoted as IP6K1-KD) acts similarly (Figure 2a). We confirmed that the stimulatory action reflects GSK3 $\beta^{\prime}$ 's effect on pCREB, as IP6K1 does not phosphorylate pCREB peptide (Supplementary Figure 3).

We assessed GSK3 $\beta$ activity in the presence of IP6K1 in vitro using the microtubule-associated protein Tau, a well-characterized GSK3 substrate, ${ }^{62}$ whose hyperphosphorylation on GSK3 sites is a prominent marker of Alzheimer's disease. ${ }^{63}$ IP6K1-WT and KD both directly activate phosphorylation of Tau by GSK3 $\beta$ (Figure 2b). Moreover, IP6K1-KD binds GSK3 $\beta$ in vitro to a similar extent as IP6K1-WT (Figure 2c).

Consistent with IP6K1's stimulation of GSK3 $\beta$ being independent of catalytic activity, IP7 (Figure 2d) or IP6 alone (data not shown) or in combination with IP6K1 fail to influence GSK3 3 .

IP6K1 binds to the N-terminal domain of GSK3, which also contains Akt phosphorylation site. We examined whether IP6K1 interferes directly with Akt's action on GSK3 in vitro. IP6K1 at $50 \mathrm{~nm}$ 

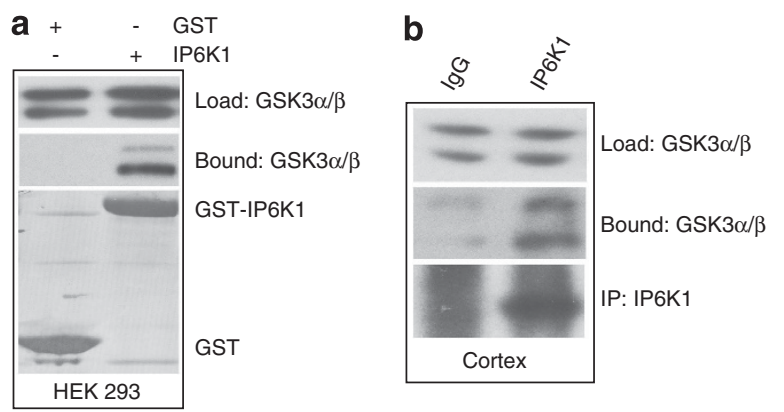

C
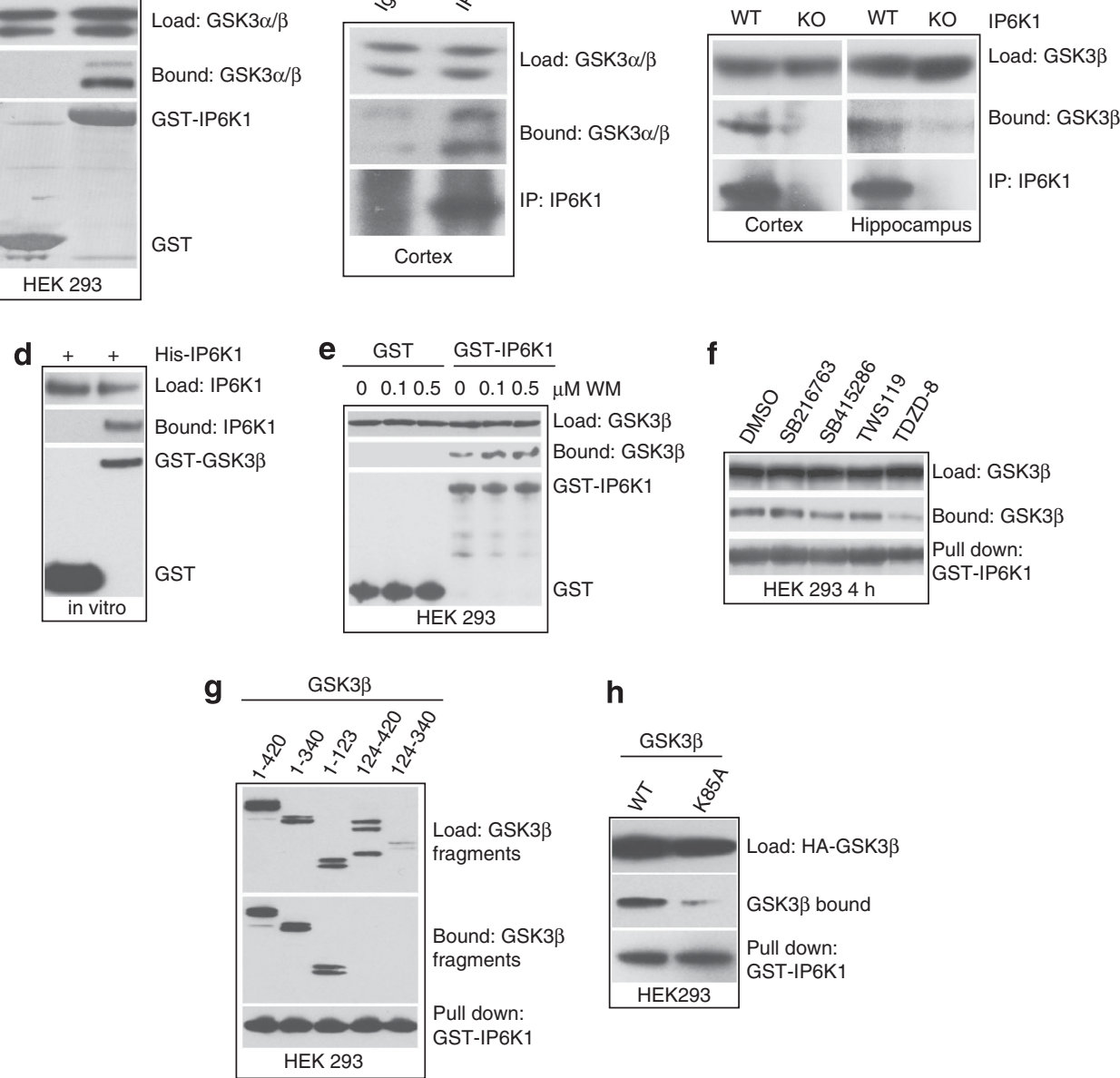

$\mathbf{h}$

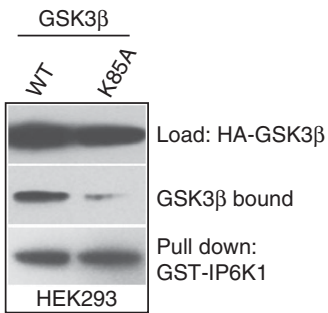

Figure 1. Inositol hexakisphosphate-1 (IP6K1) physiologically binds glycogen synthase kinase 3 (GSK3) kinase. (a) GST-IP6K1 overexpressed in HEK293 cells binds endogenous GSK3 $\alpha / \beta$. (b) IP6K1 immunoprecipitated from cortical tissue extracts co-precipitates both GSK3 $\alpha$ and $\beta$. (c) GSK3 $\beta$ is co-immunoprecipitated with IP6K1 from wild-type (WT) cortical and hippocampal tissues. IP6K1-deleted mice (IP6K1-KO) tissues were used as negative controls. (d) GST-GSK3 $\beta$ and His-IP6K1, purified from bacteria interacts in vitro. (e) Wortmannin, a PI3K inhibitor which inhibits Akt enhances GST-IP6K1-endogenous GSK3 $\beta$ interaction. (f) TDZD-8, but not other GSK3 inhibitors, disrupts GST-IP6K1 binding to endogenous GSK3 $\beta$ following 4-h treatment. (g) Deletion analysis reveals that N-teminal (1-123) residues of GSK3 $\beta$ bind IP6K1. GST-IP6K1 and Flag-GSK3 $\beta$ full-length and deleted versions were co-overexpressed in HEK293 cells. (h) Catalytically inactive GSK3 $\beta$ (K85A) does not bind IP6K1.

significantly inhibits Akt-mediated phosphorylation of GSK3 $\beta$ (Supplementary Figure 4). IP6K1-KD displays similar effects (data not shown). IP7 does not display any inhibitory effect even at $500 \mathrm{~nm}$ (data not shown), whereas it blocks PDK1-mediated Akt activation at low nM concentrations. ${ }^{34}$ As IP6K1 does not bind to Akt and IP7 is ineffective in this assay, it is possible that IP6K1 activates GSK3 by physically interfering with its phosphorylation by Akt.

\section{Targeted deletion of IP6K1 disrupts GSK3 signaling}

We assessed in vivo regulation of GSK3 activity by IP6K1 in the brain using IP6K1-KO mice. First, we explored the role of IP6K1 in the biosynthesis of inositol pyrophosphates in the brain. IP6K1 physiologically generates two forms of inositol pyrophosphates, PP-IP4 from IP5 and 5-PP-IP5 or IP7 from IP6. ${ }^{32,64,65}$ In cerebral cortical cultures from IP6K1-KO mice generation of both of these products of IP6K1 is reduced by about 50\% (Figure 3a and Supplementary Figure 5). Thus, IP6K1 is a major, though not sole source of inositol pyrophosphates in the cerebral cortex.

We monitored effects of IP6K1 deletion upon phosphorylated forms of GSK3 $\alpha / \beta$ in the cerebral cortex, hippocampus and corpus striatum of IP6K1-KO mice (Figures $3 b-d$ ). In all three brain regions, phosphorylation levels of GSK3 $\alpha$ (S21) and GSK3 $\beta$ (S9) are substantially increased in IP6K1 knockouts. The extent of augmentation is similar in the three brain regions examined but more prominent in cortex and hippocampus. By contrast, phosphorylation of Erk (T202/Y204), which is not part of the AktGSK3 pathway, is not altered in the IP6K1 knockouts. We also detect enhanced phosphorylation of Akt (T308 and S473) in IP6K1KO mice (Supplementary Figures 6a and b).

We examined, in IP6K1-KO mice, phosphorylation and stabilization of $\beta$ catenin, a GSK3 $\beta$ substrate that is targeted for degradation following its phosphorylation. ${ }^{22}$ In IP6K1-KO cortical and hippocampal extracts, we observe increased levels of total Bcatenin protein in accordance with diminished levels of phosphorylation at serines $33 / 37$ (Figures 3e-g). Despite enhanced levels of $\beta$ catenin in IP6K1 mutants, its binding to GSK3 $\beta$ is diminished indicating disruption of the complex in the absence of IP6K1 (Figure 3h).

IP6K1 deletion impacts locomotor behavior

GSK3 has been associated with the regulation of locomotor activity by lithium and drugs affecting dopamine receptor 

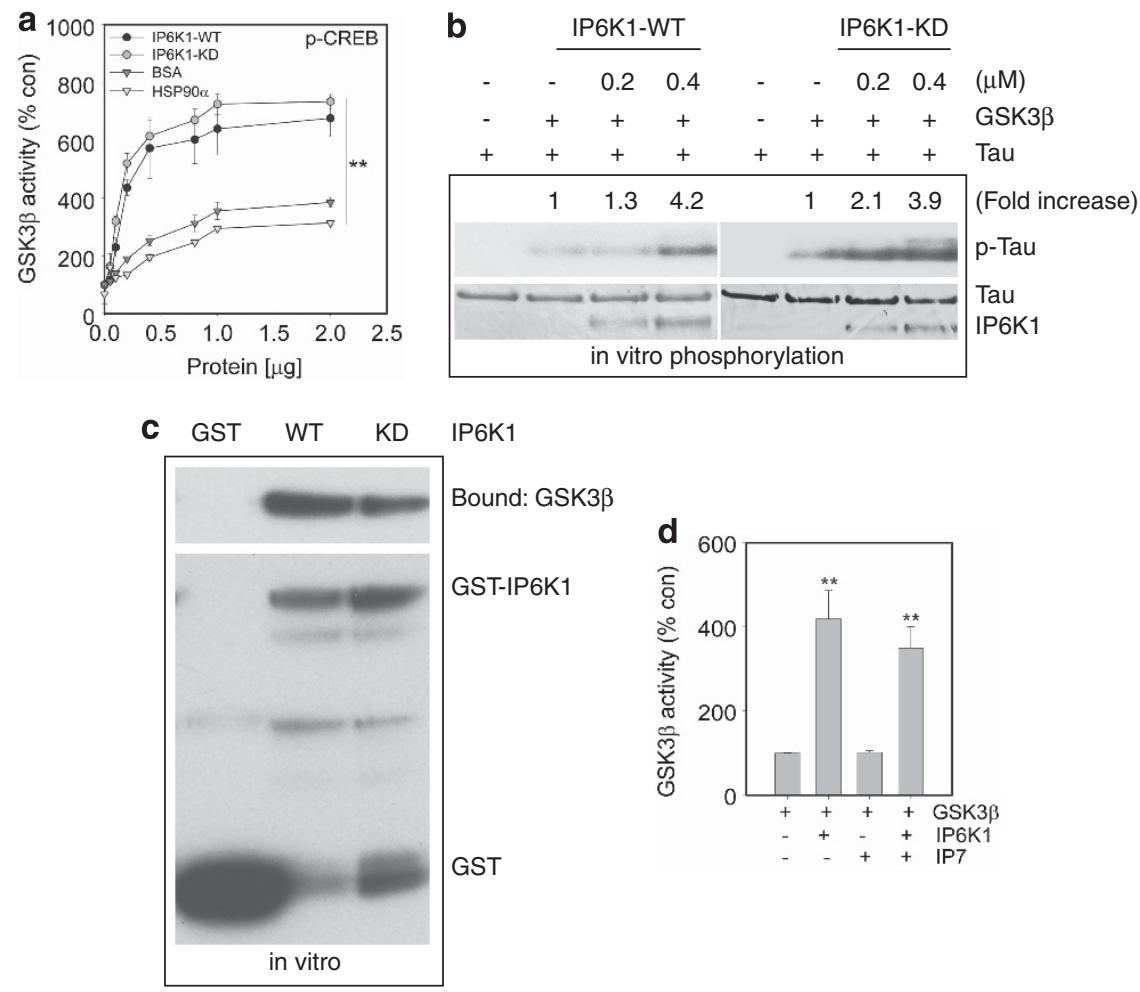

Figure 2. Inositol hexakisphosphate-1 (IP6K1) stimulates glycogen synthase kinase 3 (GSK3) kinase catalytic activity. (a) GSK3 $\beta$ catalytic activity is enhanced by indicated concentrations of purified IP6K1-wild type (WT) and IP6K1-kinase-dead (KD) in vitro. Bacterially purified GSK3 $\beta$ (20 nM) was used in the assay with pCREB peptide as a substrate. HSP90 and bovine serum albumin (BSA) were used as controls. (b) IP6K1-WT and IP6K1-KD stimulate GSK3 $\beta$ catalytic activity on Tau. Bacterially purified Tau was incubated with GSK3 $\beta$ and indicated concentrations of IP6K1 in presence of cold ATP and $\gamma[$ ATP]. Phosphorylation of Tau was detected by autoradiography after running the samples on SDSpolyacrylamide gel electrophoresis (SDS-PAGE). Protein load was determined by coommassie blue staining. (c) GST-tagged IP6K1-WT and IP6K1-KD bind recombinant purified untagged GSK3 $\beta$ to a similar extent in vitro. All the proteins were purified from bacteria. (d) IP7 alone or in combination with IP6K1 does not influence GSK3 $\beta$ activity in vitro.

signaling. ${ }^{28}$ Mice with increased activation of GSK3 $3^{53,66,67}$ display enhanced locomotor responses when placed in novel environments. In addition, GSK $3 \alpha-\mathrm{KO}$ mice manifest reduced exploratory locomotor activity in a novel environment, ${ }^{68}$ while GSK3 $\beta$ haploinsufficient mice have reduced locomotor responsiveness to amphetamine. ${ }^{53}$

Regulation of GSK3 by IP6K1 might imply similar influences upon locomotor activity. Accordingly, we examined locomotor activity of IP6K1 mutants. IP6K1-KO mice exhibit decreased basal horizontal and vertical activity in a novel environment as compared with their non-transgenic littermates (Figures $4 a$ and b). As previously shown, ${ }^{14,16}$ a similar, albeit more profound, effect on basal locomotor activity is elicited in WT mice by the selective GSK3 inhibitor TDZD-8 (Figure 4c). To rule out the possibility that changes in locomotor activity in IP6K1-KO mice reflect a more generalized deficiency in motor coordination or strength, these parameters were evaluated using an accelerating rotarod. In this test, IP6K1-KO and WT mice perform similarly (Figure 4d).

D-Amphetamine ( $2 \mathrm{mg} \mathrm{kg}^{-1}$ i.p.) elicits hyperlocomotion in both IP6K1-KO and WT mice (Figure 4e). However, the intensity of this response is reduced in $\mathrm{KO}$ animals during a $90-\mathrm{min}$ period following drug injection (Figures $4 \mathrm{f}$ and $\mathrm{g}$ ). The diminished activation of the mutant mice is most notable $30 \mathrm{~min}$ after drug treatment, while the initial response to amphetamine unaffected in the first $30 \mathrm{~min}$ (Figure $4 \mathrm{~g}$ ). Interestingly, similar changes in the dynamic response to amphetamine, occurring only $30 \mathrm{~min}$ after treatment, have also been reported in GSK3 $\beta$ haploinsufficient mice ${ }^{53}$ and are compatible with the known delayed response of Akt/GSK3 signaling to dopamine receptor stimulation. ${ }^{14}$

IP6K1 deletion disrupts social behavior

Studies using different mice models of GSK3 $\alpha$ or $\beta$ deficiency reveal that these two kinases contribute in different ways to the regulation of social behavior. Thus, complete deletion of forebrain GSK3 $\beta$ increases sociability ${ }^{56}$ and, while having no effect on its own, GSK3 $\beta$ haploinsufficiency improves social behavior in serotonin-depleted mice. ${ }^{69}$ By contrast, GSK3 $\alpha$-KO mice display a lack of interest for social interaction in the Crawley Preference for Social Novelty test (PSNT), ${ }^{68}$ a behavioral paradigm used to model 'autistic-like' social responses in rodents. ${ }^{54}$

In the PSNT, mice are placed in the central compartment of a three-compartment chamber. In the first session, the mouse can choose between visiting a compartment containing a neutral object and a compartment containing an immobilized, unfamiliar social interaction partner. In the second session of the test, the mouse is given the choice of visiting a known or new interaction partner. ${ }^{54}$ In this test, WT animals generally prefer to interact with a social partner in the first session and with a novel interaction partner in the second session. When assayed in the PSNT, IP6K1KO mice exhibit deficits (Figure $5 \mathrm{a}$ ) similar to those reported in GSK3 $\alpha-K O$ animals. ${ }^{68}$ Unlike WT mice, during the first PSNT session, IP6K1-KO mice do not prefer the chamber containing an unfamiliar mouse (Stranger 1, or S1) over a chamber containing a new object (obj) (Figure 5a, session 1). Furthermore, during the 

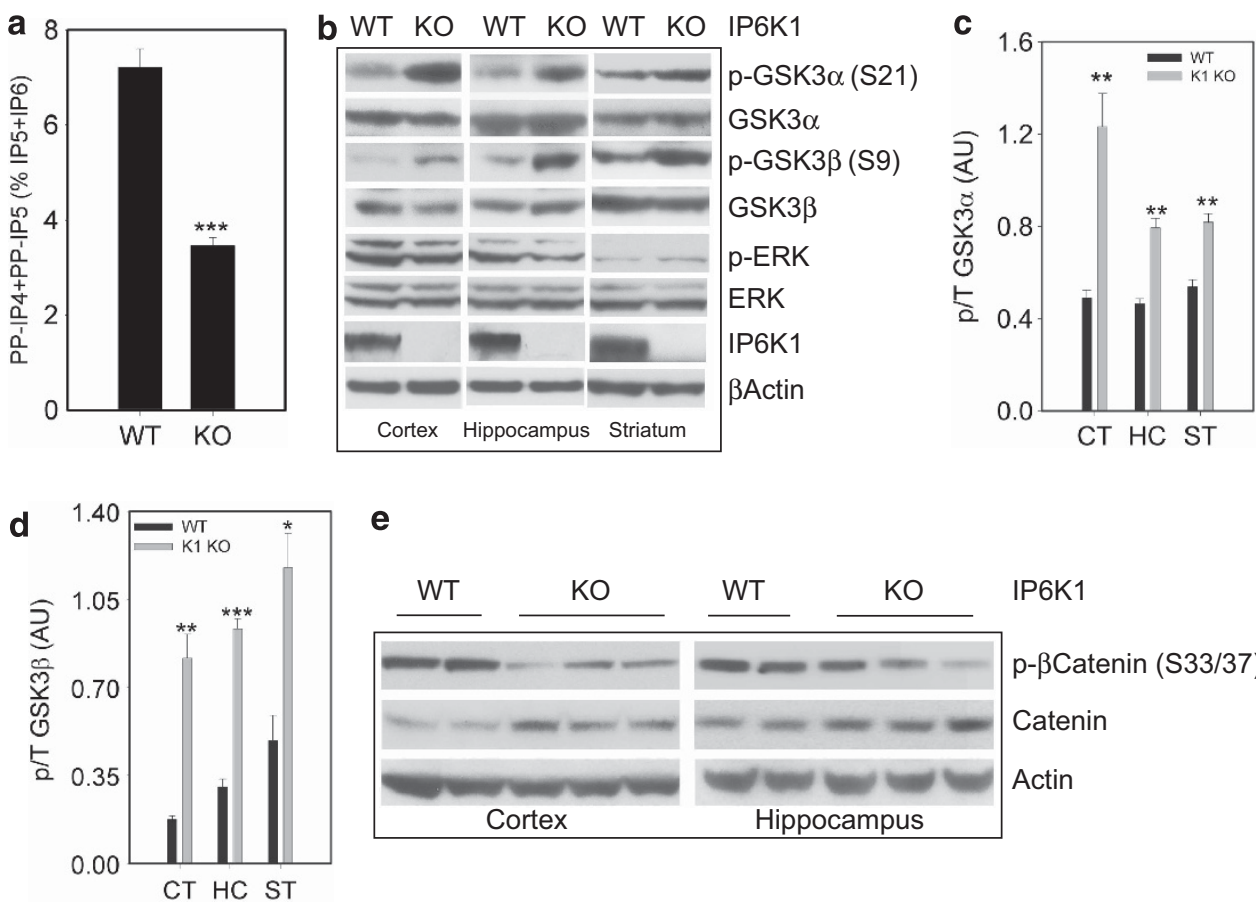

e
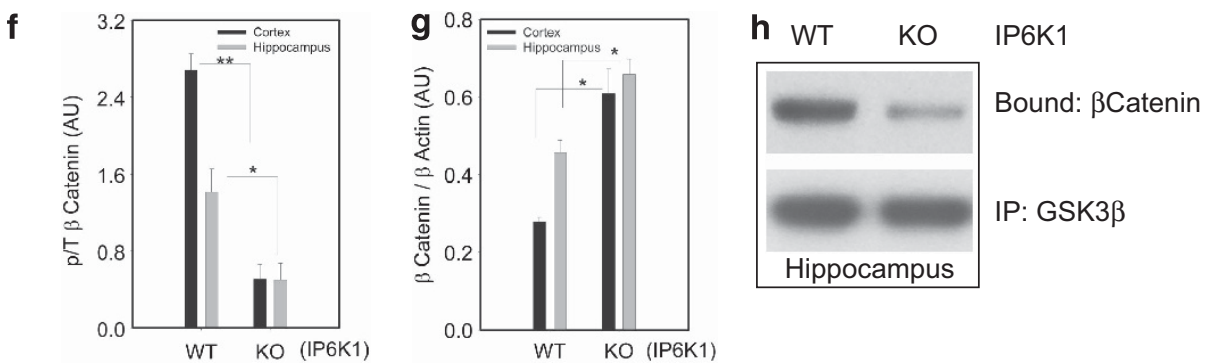

Figure 3. Targeted deletion of inositol hexakisphosphate-1 (IP6K1) disrupts glycogen synthase kinase 3 (GSK3) signaling. (a) [3H]inositol labeling of primary cortical neurons reveals 50\% reduction in inositol pyrophosphate synthesis in IP6K1-deleted mice (IP6K1-KO) cells. (b) GSK3 $\alpha / \beta$ phosphorylation is enhanced in IP6K1-KO brain tissues. Western blotting analysis was performed with similar cohorts of mice used for behavioral studies. (c) Densitometry reveals two-- to threefold increase in GSK3 $\alpha$ (S21) phosphorylation in the IP6K1-KO cortical (CT), hippocampal (HC) and striatal (ST) regions. (d) IP6K1-KO cortical, hippocampal and striatal regions display three- to fourfold enhancements in GSK3 $\beta$ (S9) phosphorylation. (e) IP6K1-KO display reduced phosphorylation and increased total protein levels of $\beta$ catenin in the hippocampal and cortical extracts. (f) Densitometry of panel e indicates four- to sixfold reductions in phospho/total $\beta$ catenin protein levels in IP6K1-KO hippocampal and cortical extracts. (g) Densitometry of panel e indicates $1.5-2.5$-fold enhancements in $\beta$ catenin/ $\beta$ Actin protein levels in IP6K1-KO hippocampal and cortical extracts. (h) Diminished binding of GSK3 $\beta$ and $\beta$ catenin in IP6K1-deleted hippocampal extracts. Equal concentrations of proteins were immunoprecipitated using $\alpha$-GSK3 $\beta$ antibody and were blotted for bound $\beta$ catenin. WT, wild type.

second phase of the test (session 2), mutant males do not explore the newly introduced mouse (Stranger 2 or S2) over a now familiar mouse (S1) (Figure 5a, session 2). This indifference to social novelty indicates reduced social motivation in the IP6KI-KO animals.

To evaluate sociability in a more socially relevant context, a social interaction test was performed in an open area where two unknown male mice, a C57BL/6 and an IP6K1-WT or KO, were free to interact with each other. We observe no difference between WT and $\mathrm{KO}$ mice in time spent in active social interaction, made up by time during which one or both mice are engaged in social activities (Figure 5b). Nevertheless, whereas C57BL/6 and WT animals initiate similar numbers of social events during the test, $\mathrm{KO}$ mice initiate fewer social events (Figure $5 \mathrm{c}$ ). To assess a possible role for global inhibition of GSK3 in this social paradigm, control WT male mice were treated with TDZD-8 or vehicle before the social interaction test (Figures $5 d$ and e). Treatment with TDZD-8 slightly decreases the total time spent in active social interaction (Figure 5d). Further examination of the interactions reveals that this overall reduction in social interactions can be attributed to diminished social events initiated by TDZD-8 treated mice (Figure 5e). Thus, inhibition of both GSK3 isoforms results in lower sociability both in mice treated with a GSK3 inhibitor and in IP6K1-KO mice.

\section{DISCUSSION}

In the present study, we demonstrate that IP6K1 physiologically regulates GSK3 kinases. IP6K1 binds and activates GSK3 both in vitro and in vivo. Catalytically inactive IP6K1 stimulates GSK3 activity as effectively as the wild-type enzyme. There is precedent for such catalytically independent actions of enzymes in the inositol polyphosphate family. Thus, inositol polyphosphate multikinase exerts both inositol phosphate kinase activity, as the biological source of inositol pentakisphophate (IP5) as well as manifesting $\mathrm{PI} 3$ kinase activity. ${ }^{70}$ Additionally, independent of its 
a

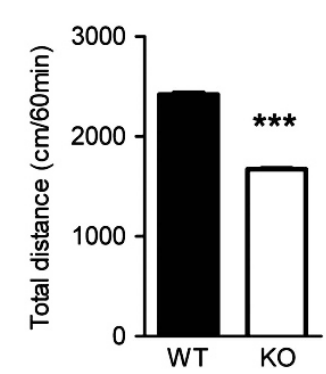

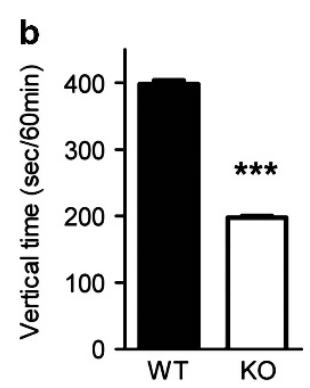

c

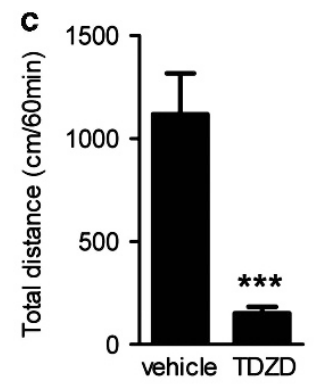

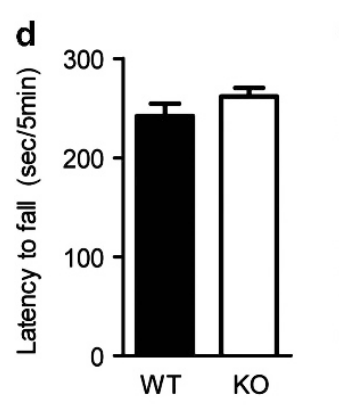
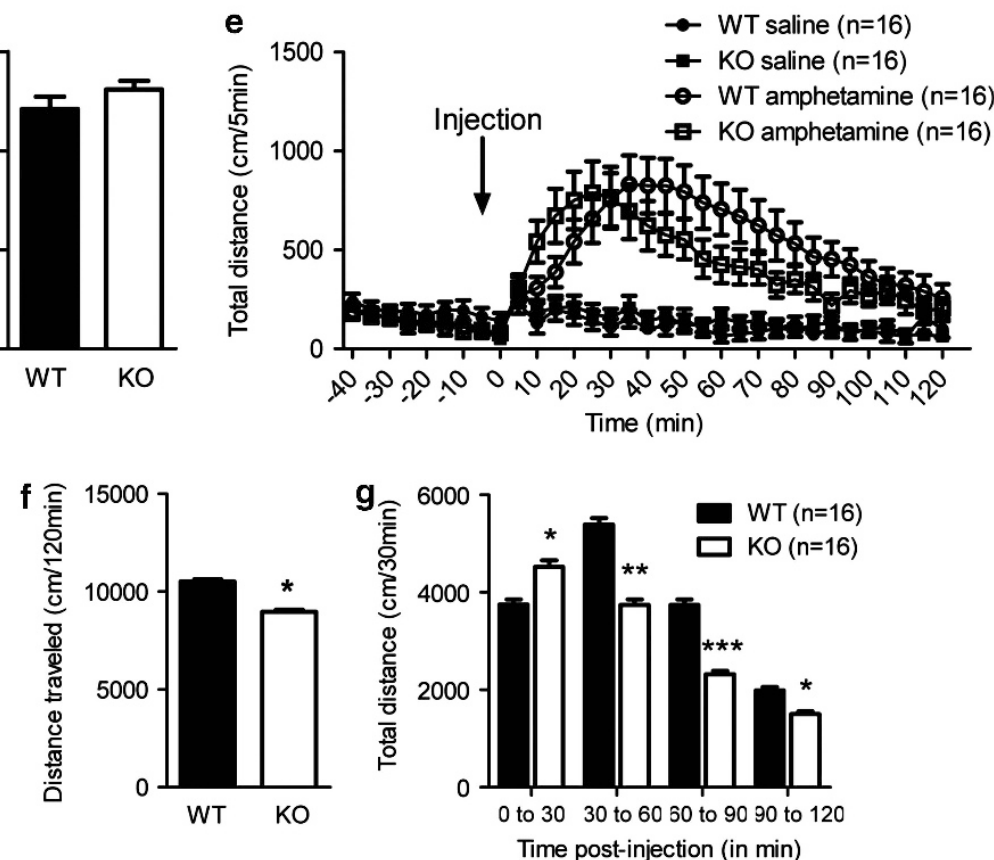

Figure 4. IP6K1-deleted mice (IP6K1-KO) mice display reduced activity in a novel environment. (a) Total distance traveled for wild type (WT) $(n=15)$ and KO $(n=16)$ in $60 \mathrm{~min}$. (b) Total vertical time for WT $(n=15)$ and KO $(n=16)$ in 60 min. (c) Total distance traveled in 60 min by WT mice in response to vehicle $(n=7)$ or TDZD-8 $(n=7)$ treatment $\left(30 \mathrm{mg} \mathrm{kg}^{-1}\right)$. (d) Accelerated rotarod experiment in WT $(n=15)$ and KO

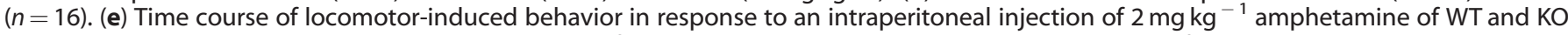
mice, expressed in distance traveled per 5-min blocks. (f) Cumulative distance traveled during the 90 min after amphetamine treatment in WT $(n=16)$ and KO $(n=16)$ mice. (g) Cumulative distance traveled per 30 min periods after amphetamine treatment in WT $(n=16)$ and KO $(n=16)$ mice.

catalytic activity, inositol polyphosphate multikinase physiologically stabilizes the mTOR1 complex to stimulate protein synthesis. ${ }^{71}$ Moreover, IP6K1 regulates dopamine release in a catalytically independent manner. ${ }^{50}$

In contrast to the ability of kinase-dead IP6K1 to activate GSK3, catalytic activity of GSK3 is required for binding to IP6K1. Thus, three distinct inhibitors of GSK3 substantially decrease IP6K1GSK3 $\beta$ binding. Moreover, kinase-dead GSK3 $\beta$ binds much less to IP6K1 than the wild-type enzyme. These findings suggest that IP6K1 binds selectively to the catalytically active form of GSK3. Alternatively, IP6K1 binding may stabilize the active conformation of GSK3 $\beta$.

In our earlier studies, we established that IP7 generated by IP6K1 physiologically regulates $\mathrm{Akt}^{34}$ Thus, at low nM concentrations, IP7 inhibits the phosphorylation and activation of Akt by PDK1, whereas Akt activity is greatly augmented and GSK activity is reduced in IP6K1-deleted mice. ${ }^{34}$ Findings of the present study establish a complementary mode of GSK3 regulation by IP6K1, which non-catalytically provides direct activation of GSK3. Augmentation of GSK3 signaling involving two distinct - catalytic versus non-catalytic - actions of IP6K1 implies biological importance for this system (Figure 6).
Evidence for a physiological role of IP6K1 in regulating GSK3 in the brain with attendant behavioral sequelae comes from our experiments showing reduced GSK3 activity in brains of IP6K1 mutants. Behavioral responses of IP6K1-KO mice are reminiscent of several mouse models of GSK3 deficiency as well as of normal animals treated with GSK3 inhibitors.

Reductions in locomotor responsiveness to amphetamine similar to those observed in IP6K1-KO mice, have been reported in haploinsufficient GSK3 $\beta$ mice. ${ }^{53}$ Reduced social interactions have been detected in GSK3 $\alpha-\mathrm{KO}$ mice. ${ }^{68}$ Interestingly, reduction of GSK3 $\beta$ activity has been reported to exert virtually opposite effects, enhancing sociability, ${ }^{56}$ suggesting that GSK3 isoforms may have different roles in modulating behavior. However, WT mice treated with a GSK3 inhibitor TDZD-8 display similar effect (Figure 5e) as IP6K1-KOs, which indicates that global inhibition of GSK3 disrupts social interactions.

Diminished GSK3 activity and related behavioral consequences in IP6K1-KO mice may reflect combined effects of IP7 on Akt and IP6K1 on GSK3. Though we examined both mechanisms in vitro, it is difficult to assess to what extent each contributes in vivo, because readouts for both phenomena are the same. Depending on regional ${ }^{56}$ or cellular contexts, each pathway may contribute 


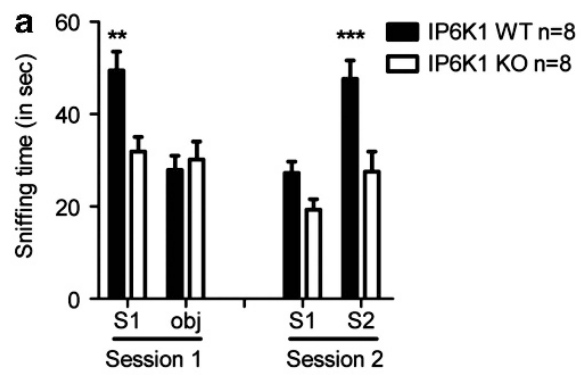

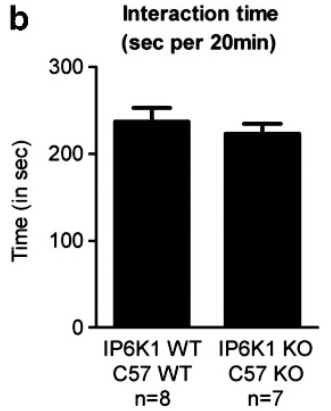
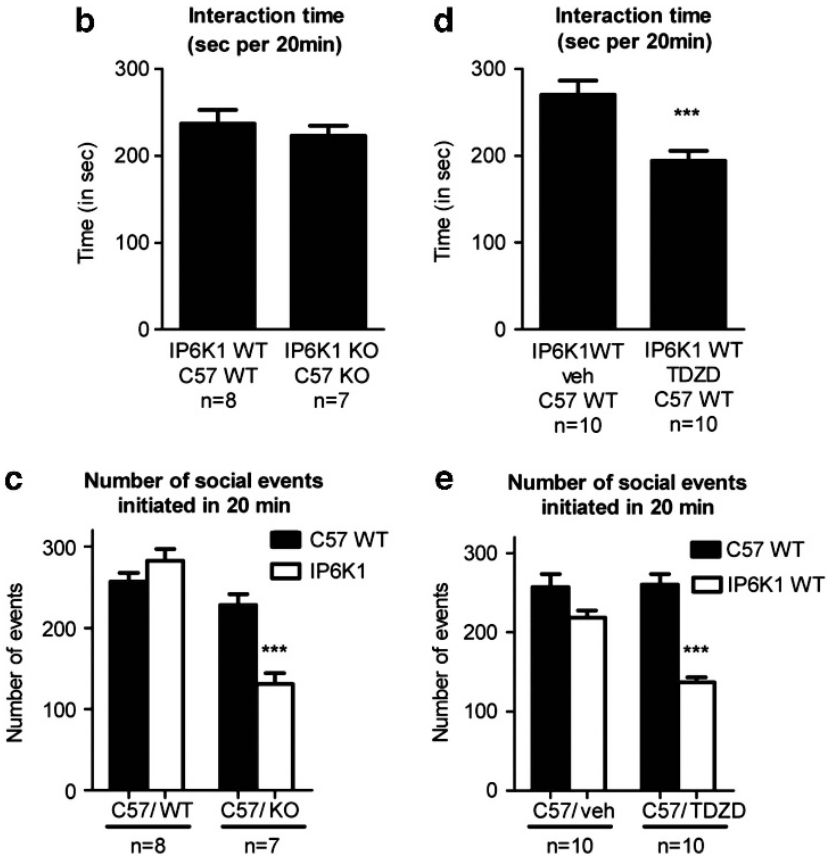

Figure 5. Preference for social novelty and social interactions in IP6K1-deleted mice (IP6K1-KOs). (a) Effect of IP6K1-KO on social preference and recognition. Average interaction time spent with a C57BL/6 stranger mouse (S1 or S2) or an object (obj) during the place preference for IP6K1-wild type (WT) $(n=8)$ and KO $(n=8)$. (b) Average time (in seconds) spent in active social interaction during a 20-min period for IP6K1-KO, IP6K1-WT mice and their C57BL/6 social interaction partners ( $n=7-8$ mice in each group). (c) Number of social events initiated by IP6K1-KO, IP6K1-WT mice and their C57BL/6 social interaction partners during the entire testing session $(n=7-8$ mice in each group). (d) Average time (in seconds) spent in active social interaction during a 20-min period for IP6K1-WT mice treated with vehicle or TDZD-8 (10 mg kg ${ }^{-1}$ intraperitoneally) and their noninjected C57BL/6 social interaction partners $(n=10$ mice in each group). (e) Number of social events initiated by TDZD-8 or vehicletreated IP6K1-WT mice and their non-injected C57BL/6 social interaction partners ( $n=10$ mice in each group).

differently. Furthermore, binding of IP6K1 may also prevent GSK3 inhibition by other kinases that have been shown to phosphorylate the N-terminal region of GSK3. ${ }^{3}$ In contrast, IP7 inhibition of Akt globally diminishes the phosphorylation of its substrates, including GSK3. Moreover, IP6K1 binding prevents Aktmediated GSK3 phosphorylation, indicating that Akt activation alone may not suffice to inhibit GSK3 activity in vivo and that disruption IP6K1-GSK3 binding may also necessary. Thus, both mechanisms seem to participate in GSK3 activation and do so in a coordinated fashion. Knock-in studies with mutants of IP6K1 that are catalytically inactive or unable to bind GSK3 may be necessary to dissect the specific consequences of IP7 and IP6K1 mechanisms in the regulation of behavior.

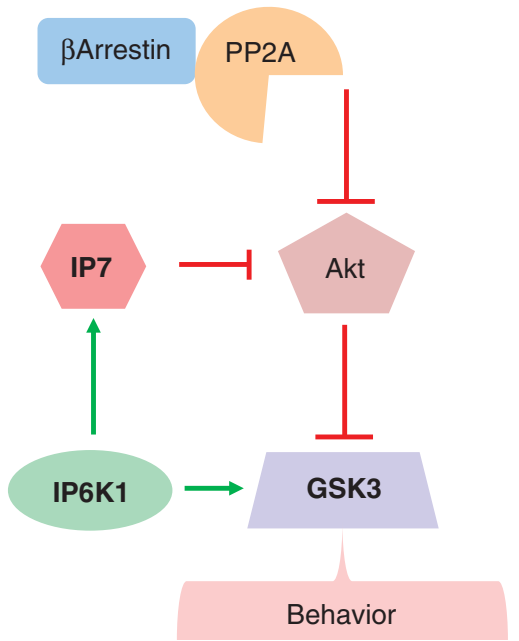

Figure 6. Barrestin/PP2A complex inhibits Akt and activates glycogen synthase kinase $\beta$ (GSK $\beta$ ) in response to dopamine signaling via D2 receptors. Inositol hexakisphosphate-1 (IP6K1) generates IP7, which inhibits overactivation of Akt thus enhancing GSK3. IP6K1 directly binds and activates GSK3. Thus, targeting IP6K1 activity and/ or its binding to GSK3 may improve psychiatric symptoms via GSK3 regulation.

Obesity and related metabolic syndromes are risk factors for mental disorders ${ }^{72,73}$ and neurodegenerative diseases such as Alzheimer's disease. ${ }^{74,75}$ GSK3 activity is increased in obesity, type 2 diabetes and neurodegeneration and thus, is considered as a common link in metabolic disorders and neurodegeneration via phosphorylationmediated regulation of various targets such as glycogen synthase, Bcatenin, Tau and Bamyloid. ${ }^{75,76}$ Therefore, IP6K1 regulation of GSK3 via $\mathrm{Akt}^{34}$ or by direct binding may differentially regulate GSK3 targets in various disease conditions or provide an avenue to understand comorbidities of neurological and metabolic diseases.

Abnormalities in insulin signaling pathways have been demonstrated in various psychiatric ${ }^{77}$ and neurodegenerative diseases. ${ }^{78}$ Second-generation antipsychotics display metabolic side effects of which weight gain is the most prominent. ${ }^{79}$ IP6K1-KO mice are protected against age and high-fat diet-induced insulin resistance and obesity. ${ }^{34}$ Thus, IP6K1 modulators alone or in combination might beneficially modulate insulin signaling pathway and suppress weight gain. ${ }^{33}$ Drugs that inhibit IP6K1 activity or disrupt its binding to GSK3 may exert beneficial effects in schizophrenics based on the reported diminution of Akt/GSK3 signaling in schizophrenic patient brain and the augmented Akt signaling in IP6K1 mutant mice.

Furthermore, enhanced stability of $\beta$ catenin in IP6K1-KO mice as a result of its reduced binding with GSK3 $\beta$ (Figures $3 g$ and $h$ ) implies regulation of the Wnt complex stability by IP6K1. IP6K1 binding may specifically impact Wnt-mediated GSK3, whereas IP7 might reduce Akt activity with global effects on Akt substrates, notably GSK3. Further characterization of IP7-Akt and IP6K1-GSK3 complexes may clarify cross-talk mechanisms regulating IP6K1 in Wnt and insulin signaling pathway.

In conclusion, our data indicate that IP6K1 can activate brain GSK3 isoforms via two parallel mechanisms. Our findings also indicate that the control of GSK3 isoforms by IP6K1 can contribute to behavioral regulation by GSK3 $\alpha$ and $\beta$. Accordingly, modulation of brain IP6K1 may represent a previously unexplored avenue for the management of mental disorders associated with aberrant regulation of GSK3 activity.

\section{CONFLICT OF INTEREST}

The authors declare no conflict of interest. 


\section{ACKNOWLEDGEMENTS}

We thank Lynda Hester for primary neuronal cultures; Masoumeh Saleh, Kathye Aubée and Nathalie Bouchard for mouse colony maintenance; Adele Snowman and Akrita Bhatnagar for protein purification; Krishna Juluri for providing human IP6K1 bacterial expression constructs and James Barrow for kindly providing synthetic IP7 for assay. This work was supported by US Public Health Service Grants MH18501 and DA-000266 (to SHS) and a Canadian Institutes of Health Research (CIHR, to JMB). JMB holds a Canada Research Chair in Molecular Psychiatry and is NARSAD Vital Projects Fund investigator

\section{REFERENCES}

1 Sutherland C, Leighton IA, Cohen P. Inactivation of glycogen synthase kinase-3 beta by phosphorylation: new kinase connections in insulin and growth-factor signalling. Biochem J 1993; 296: 15-19.

2 Saito Y, Vandenheede JR, Cohen P. The mechanism by which epidermal growth factor inhibits glycogen synthase kinase 3 in A431 cells. Biochem J 1994; 303: 27-31.

3 Stambolic V, Woodgett JR. Mitogen inactivation of glycogen synthase kinase-3 beta in intact cells via serine 9 phosphorylation. Biochem J 1994; 303: 701-704.

4 Kaidanovich-Beilin O, Beaulieu JM, Jope RS, Woodgett JR. Neurological functions of the masterswitch protein kinase - gsk-3. Front Mol Neurosci 2012; 5: 48.

5 Cantley LC. The phosphoinositide 3-kinase pathway. Science 2002; 296: 1655-1657.

6 Alessi DR, James SR, Downes CP, Holmes AB, Gaffney PR, Reese CB et al. Characterization of a 3-phosphoinositide-dependent protein kinase which phosphorylates and activates protein kinase Balpha. Curr Biol 1997; 7: 261-269.

7 Sarbassov DD, Guertin DA, Ali SM, Sabatini DM. Phosphorylation and regulation of Akt/PKB by the rictor-mTOR complex. Science 2005; 307: 1098-1101.

8 Cross DA, Alessi DR, Cohen P, Andjelkovich M, Hemmings BA. Inhibition of glycogen synthase kinase-3 by insulin mediated by protein kinase B. Nature 1995; 378: 785-789.

9 Frame S, Cohen P, Biondi RM. A common phosphate binding site explains the unique substrate specificity of GSK3 and its inactivation by phosphorylation. Mol Cell 2001; 7: 1321-1327.

10 Beaulieu JM. A role for Akt and glycogen synthase kinase-3 as integrators of dopamine and serotonin neurotransmission in mental health. J Psychiatry Neurosci 2012; 37: 7-16.

11 Tan HY, Chen AG, Kolachana B, Apud JA, Mattay VS, Callicott JH et al. Effective connectivity of AKT1-mediated dopaminergic working memory networks and pharmacogenetics of anti-dopaminergic treatment. Brain 2012; 135: 1436-1445.

12 Lohse MJ, Benovic JL, Codina J, Caron MG, Lefkowitz RJ. beta-Arrestin: a protein that regulates beta-adrenergic receptor function. Science 1990; 248: 1547-1550.

13 Ferguson SS, Downey III WE, Colapietro AM, Barak LS, Ménard L, Caron MG. Role of beta-arrestin in mediating agonist-promoted $\mathrm{G}$ protein-coupled receptor internalization. Science 1996; 271: 363-366.

14 Beaulieu JM, Sotnikova TD, Marion S, Lefkowitz RJ, Gainetdinov RR, Caron MG. An Akt/beta-arrestin 2/PP2A signaling complex mediates dopaminergic neurotransmission and behavior. Cell 2005; 122: 261-273.

15 Luttrell LM, Ferguson SS, Daaka Y, Miller WE, Maudsley S, Della Rocca GJ et al. Beta-arrestin-dependent formation of beta2 adrenergic receptor-Src protein kinase complexes. Science 1999; 283: 655-661.

16 Beaulieu JM, Gainetdinov RR, Caron MG. Akt/GSK3 signaling in the action of psychotropic drugs. Annu Rev Pharmacol Toxicol 2009; 49: 327-347.

17 Beaulieu JM, Marion S, Rodriguiz RM, Medvedev IO, Sotnikova TD, Ghisi V et al. A beta-arrestin 2 signaling complex mediates lithium action on behavior. Cell 2008; 132: $125-136$.

18 O'Brien WT, Huang J, Buccafusca R, Garskof J, Valvezan AJ, Berry GT et al. Glycogen synthase kinase- 3 is essential for $\beta$-arrestin- 2 complex formation and lithium-sensitive behaviors in mice. J Clin Invest 2011; 121: 3756-3762.

19 Klein PS, Melton DA. A molecular mechanism for the effect of lithium on development. Proc Natl Acad Sci USA. 1996; 93: 8455-8459.

20 Stambolic V, Ruel L, Woodgett JR. Lithium inhibits glycogen synthase kinase-3 activity and mimics wingless signalling in intact cells. Curr Biol 1996; 6: 1664-1668.

21 Dale TC. Signal transduction by the Wnt family of ligands. Biochem J 1998; 329: 209-223.

22 Wu D, Pan W. GSK3: a multifaceted kinase in Wnt signaling. Trends Biochem Sci 2010; 35: 161-168.

23 Logan CY, Nusse R. The Wnt signaling pathway in development and disease. Annu Rev Cell Dev Biol 2004; 20: 781-810.

24 Freyberg Z, Ferrando SJ, Javitch JA. Roles of the Akt/GSK-3 and Wnt signaling pathways in schizophrenia and antipsychotic drug action. Am J Psychiatry 2010; 167: 388-396.

25 Kvajo M, McKellar H, Gogos JA. Molecules, signaling, and schizophrenia. Curr Top Behav Neurosci 2010; 4: 629-656.
26 Emamian ES, Hall D, Birnbaum MJ, Karayiorgou M, Gogos JA. Convergent evidence for impaired AKT1-GSK3beta signaling in schizophrenia. Nat Genet 2004; 36: 131-137.

27 Tan HY, Nicodemus KK, Chen Q, Li Z, Brooke JK, Honea R et al. Genetic variation in AKT1 is linked to dopamine-associated prefrontal cortical structure and function in humans. J Clin Invest 2008; 118: 2200-2208.

28 Beaulieu JM, Gainetdinov RR. The physiology, signaling, and pharmacology of dopamine receptors. Pharmacol Rev. 2011; 63: 182-217.

29 Li YC, Xi D, Roman J, Huang YQ, Gao WJ. Activation of glycogen synthase kinase-3 beta is required for hyperdopamine and D2 receptor-mediated inhibition of synaptic NMDA receptor function in the rat prefrontal cortex. J Neurosci 2009; 29: 15551-15563.

30 Peineau S, Bradley C, Taghibiglou C, Doherty A, Bortolotto ZA, Wang YT et al. The role of GSK-3 in synaptic plasticity. Br J Pharmacol 2008; 153:(Suppl 1): S428-S437.

31 Berridge MJ, Lipp P, Bootman MD. The versatility and universality of calcium signalling. Nat Rev Mol Cell Biol 2000; 1: 11-21.

32 Saiardi A. Cell signalling by inositol pyrophosphates. Subcell Biochem 2012; 59: 413-443.

33 Chakraborty A, Kim S, Snyder SH. Inositol pyrophosphates as mammalian cell signals. Sci Signal 2011; 4: re1.

34 Chakraborty A, Koldobskiy MA, Bello NT, Maxwell M, Potter JJ, Juluri KR et al. Inositol pyrophosphates inhibit Akt signaling, regulate insulin sensitivity and weight gain. Cell 2010; 143: 897-910.

35 Illies C, Gromada J, Fiume R, Leibiger B, Yu J, Juhl K et al. Requirement of inositol pyrophosphates for full exocytotic capacity in pancreatic beta cells. Science 2007; 318: 1299-1302.

36 Szijgyarto Z, Garedew A, Azevedo C, Saiardi A. Influence of inositol pyrophosphates on cellular energy dynamics. Science 2011; 334: 802-805.

37 Prasad A, Jia Y, Chakraborty A, Li Y, Jain SK, Zhong J et al. Inositol hexakisphosphate kinase 1 regulates neutrophil function in innate immunity by inhibiting phosphatidylinositol-(3,4,5)-trisphosphate signaling. Nat Immunol 2011; 12: 752-760.

38 Sarmah B, Wente SR. Inositol hexakisphosphate kinase-2 acts as an effector of the vertebrate Hedgehog pathway. Proc Natl Acad Sci USA 2010; 107: 19921-19926.

39 York SJ, Armbruster BN, Greenwell P, Petes TD, York JD. Inositol diphosphate signaling regulates telomere length. J Biol Chem 2005; 280: 4264-4269.

40 Saiardi A, Resnick AC, Snowman AM, Wendland B, Snyder SH. Inositol pyrophosphates regulate cell death and telomere length through phosphoinositide 3-kinase-related protein kinases. Proc Natl Acad Sci USA. 2005; 102: 1911-1914.

41 Lee YS, Mulugu S, York JD, O'Shea EK. Regulation of a cyclin-CDK-CDK inhibitor complex by inositol pyrophosphates. Science 2007; 316: 109-112.

42 Morrison BH, Bauer JA, Kalvakolanu DV, Lindner DJ. Inositol hexakisphosphate kinase 2 mediates growth suppressive and apoptotic effects of interferon-beta in ovarian carcinoma cells. J Biol Chem 2001; 276: 24965-24970.

43 Nagata E, Luo HR, Saiardi A, Bae Bl, Suzuki N, Snyder SH. Inositol hexakisphosphate kinase-2, a physiologic mediator of cell death. J Biol Chem 2005; 280: 1634-1640.

44 Koldobskiy MA, Chakraborty A, Werner Jr JK, Snowman AM, Juluri KR, Vandiver MS et al. p53 mediated apoptosis requires inositol hexakisphosphate kinase-2. Proc Natl Acad Sci USA 2010; 107: 20947-20951.

45 Chakraborty A, Koldobskiy MA, Sixt KM, Juluri KR, Mustafa AK, Snowman AM et al. HSP90 regulates cell survival via inositol hexakisphosphate kinase-2. Proc Natl Acad Sci USA 2008; 105: 1134-1139.

46 Chakraborty A, Werner Jr JK, Koldobskiy MA, Mustafa AK, Juluri KR, Pietropaoli J et al. Casein kinase-2 mediates cell survival through phosphorylation and degradation of inositol hexakisphosphate kinase-2. Proc Natl Acad Sci USA. 2011 108: 2205-2209.

47 Saiardi A, Erdjument-Bromage H, Snowman AM, Tempst P, Snyder SH. Synthesis of diphosphoinositol pentakisphosphate by a newly identified family of higher inositol polyphosphate kinases. Curr Biol 1999; 9: 1323-1326.

48 Saiardi A, Bhandari R, Resnick AC, Snowman AM, Snyder SH. Phosphorylation of proteins by inositol pyrophosphates. Science 2004; 306: 2101-2105.

49 Bhandari R, Sairdi A, Ahmadibeni Y, Snowman AM, Resnick AC, Kristiansen TZ et al. Protein pyrophosphorylation by inositol pyrophosphates is a posttranslational event. Proc Natl Acad Sci USA 2007; 104: 15305-15310.

50 Luo HR, Saiardi A, Nagata E, Ye K, Yu H, Jung TS et al. GRAB: a physiologic guanine nucleotide exchange factor for Rab3A, which interacts with inositol hexakisphosphate kinase. Neuron 2001; 31: 439-451.

51 Bhandari R, Juluri KR, Resnick AC, Snyder SH. Gene deletion of inositol hexakisphosphate kinase 1 reveals inositol pyrophosphate regulation of insulin secretion, growth, and spermiogenesis. Proc Natl Acad Sci USA 2008; 105: 2349-2353.

52 Safrany ST, Shears SB. Turnover of bis-diphosphoinositol tetrakisphosphate in a smooth muscle cell line is regulated by beta2-adrenergic receptors through a cAMP-mediated, A-kinase-independent mechanism. EMBO J 1998; 17: 1710-1716. 
53 Beaulieu JM, Sotnikova TD, Yao WD, Kockeritz L, Woodgett JR, Gainetdinov RR et al. Lithium antagonizes dopamine-dependent behaviors mediated by an AKT/ glycogen synthase kinase 3 signaling cascade. Proc Natl Acad Sci USA 2004; 101: 5099-5104.

54 Moy SS, Nadler JJ, Perez A, Barbaro RP, Johns JM, Magnuson TR et al. Sociability and preference for social novelty in five inbred strains: an approach to assess autistic-like behavior in mice. Genes Brain Behav 2004; 3: 287-302.

55 Guitton MJ, Kin Y, Dudai Y. Taste-dependent sociophobia: when food and company do not mix. Behav Brain Res 2008; 191: 148-152.

56 Latapy C, Rioux V, Guitton MJ, Beaulieu JM. Selective deletion of forebrain glycogen synthase kinase $3 \beta$ reveals a central role in serotonin-sensitive anxiety and social behaviour. Philos Trans $R$ Soc Lond B Biol Sci 2012; 367: 2460-2474.

57 Sanchez S, Sayas CL, Lim F, Diaz-Nido J, Avila J, Wandosell F. The inhibition of phosphatidylinositol-3-kinase induces neurite retraction and activates GSK3. J Neurochem 2001; 78: 468-481.

58 Martinez A, Alonso M, Castro A, Pérez C, Moreno FJ. First non-ATP competitive glycogen synthase kinase 3 beta (GSK-3beta) inhibitors: thiadiazolidinones (TDZD) as potential drugs for the treatment of Alzheimer's disease. J Med Chem 2002; 45: 1292-1299.

59 Doble BW, Woodgett JR. GSK-3: tricks of the trade for a multi-tasking kinase. J Cell Sci 2003; 116: 1175-1186.

60 Fiol CJ, William JS, Chou CH, Wang QM, Roach PJ, Andrisani OM. A secondary phosphorylation of CREB341 at Ser129 is required for the CAMP-mediated control of gene expression. A role for glycogen synthase kinase-3 in the control of gene expression. J Biol Chem 1994; 269: 32187-32193.

61 Lochhead PA, Kinstrie R, Sibbet G, Rawjee T, Morrice N, Cleghon VA. chaperonedependent GSK3beta transitional intermediate mediates activation-loop autophosphorylation. Mol Cell 2006; 24: 627-633.

62 Sperber BR, Leight S, Goedert M, Lee VM. Glycogen synthase kinase-3 beta phosphorylates tau protein at multiple sites in intact cells. Neurosci Lett 1995; 197: 149-153.

63 Hernández F, de Barreda EG, Fuster-Matanzo A, Goñi-Oliver P, Lucas JJ, Avila J. The role of GSK3 in Alzheimer disease. Brain Res Bull 2009; 80: 248-250.

64 Shears SB. Diphosphoinositol polyphosphates: metabolic messengers? Mol Pharmacol 2009; 76: 236-252.

65 Barker CJ, Illies C, Gaboardi GC, Berggren PO. Inositol pyrophosphates: structure enzymology and function. Cell Mol Life Sci. 2009; 66: 3851-3871.
66 Polter A, Beurel E, Yang S, Garner R, Song L, Miller CA et al. Deficiency in the inhibitory serine-phosphorylation of glycogen synthase kinase-3 increases sensitivity to mood disturbances. Neuropsychopharmacology 2010; 35: 1761-1774.

67 Prickaerts J, Moechars D, Cryns K, Lenaerts I, van Craenendonck H, Goris I et al. Transgenic mice overexpressing glycogen synthase kinase 3beta: a putative model of hyperactivity and mania. J Neurosci 2006; 26: 9022-9029.

68 Kaidanovich-Beilin O, Lipina TV, Takao K, van Eede M, Hattori S, Laliberté C et al. Abnormalities in brain structure and behavior in GSK-3alpha mutant mice. Mol Brain 2009; 2: 35.

69 Beaulieu JM, Zhang X, Rodriguiz RM, Sotnikova TD, Cools MJ, Wetsel WC et al. Role of GSK3 beta in behavioral abnormalities induced by serotonin deficiency. Proc Natl Acad Sci USA 2008; 105: 1333-1338.

70 Resnick AC, Snowman AM, Kang BN, Hurt KJ, Snyder SH, Saiardi A. Inositol polyphosphate multikinase is a nuclear PI3-kinase with transcriptional regulatory activity. Proc Natl Acad Sci USA. 2005; 102: 12783-12788.

71 Kim S, Kim SF, Maag D, Maxwell MJ, Resnick AC, Juluri KR et al. Amino acid signaling to mTOR mediated by inositol polyphosphate multikinase. Cell Metab 2011; 13: 215-221.

72 Megna JL, Schwartz TL, Siddiqui UA, Herrera Rojas M. Obesity in adults with serious and persistent mental illness: a review of postulated mechanisms and current interventions. Ann Clin Psychiatry 2011; 23: 131-140.

73 Kaidanovich-Beilin O, Cha DS, Mclntyre RS. Crosstalk between metabolic and neuropsychiatric disorders. F1000 Biol Rep 2012; 4: 14.

74 Naderali EK, Ratcliffe SH, Dale MC. Obesity and Alzheimer's disease: a link between body weight and cognitive function in old age. Am J Alzheimers Dis Other Demen 2009; 24: 445-449.

75 Jope RS, Johnson GV. The glamour and gloom of glycogen synthase kinase-3. Trends Biochem Sci 2004; 29: 95-102.

76 Sutherland C. What are the bona fide GSK3 substrates? Int J Alzheimers Dis 2011; 2011: 505-607.

77 Girgis RR, Javitch JA, Lieberman JA. Antipsychotic drug mechanisms: links between therapeutic effects, metabolic side effects and the insulin signaling pathway. Mol Psychiatry 2008; 13: 918-929.

78 Steen E, Terry BM, Rivera EJ, Cannon JL, Neely TR, Tavares R et al. Impaired insulin and insulin-like growth factor expression and signaling mechanisms in Alzheimer's disease--is this type 3 diabetes? J Alzheimers Dis 2005; 7: 63-80.

79 Weiden PJ. Switching antipsychotics as a treatment strategy for antipsychoticinduced weight gain and dyslipidemia. J Clin Psychiatry 2007; 68: 34-39.

Supplementary Information accompanies the paper on the Molecular Psychiatry website (http://www.nature.com/mp) 